\title{
Effect of lower extremity resistance exercise on gait performance in a patient with systemic lupus erythematosus with cerebral infarction and lower extremity vasculitis: a case study
}

\author{
Yongseop $\mathrm{Oh}^{\mathrm{a}}$, Youngkeun Woo \\ ${ }^{a}$ Department of Physical Therapy, Prime Rehabilitation and Pain Clinic, Seongnam, Republic of Korea \\ ${ }^{b}$ Department of Physical Therapy, College of Medical Science, Jeonju University, Jeonju, Republic of Korea
}

Objective: This study was conducted to investigate the effects of resistant exercise on the gait performance of a patient with systemic lupus erythematosus (SLE) patient.

\section{Design: A case study.}

Methods: A 30-year-old male adult who had been diagnosed with systemic lupus erythmatosus (SLE) in April 2013, right middle cerebral artery infarction, and with left hemiplegia agreed to participate in this case study. Patient was unable to walk due to being affected with adynamia. Due to developing necrotizing vasculitis on the left lower extremity, patient underwent a myotomy on the left thigh. The patient was trained with a progressive resistant exercise program for 8 weeks. An intensity of 15 RM was used for the resistant exercises and the resistance level was increased progressively in order to improve the muscle power of the patient. Methods used to increase resistance included changing positions, providing mechanical resistance instead of manual resistance, transitioning from open kinetic chain to closed kinetic chain exercises, and changing the colors of the theraband to those with increase level of resistance. Outcome measures included the 5-repetition sit-to- stand test (5RSST), Timed Up \& Go (TUG), and 10 -meter walk test (10MWT). In addition, the GAITRite was used to assess the spatio-temporal gait variables, including gait speed, cadence, stride length of the left side, and double limb support pre and post-intervention.

Results: The patient was able to perform sit-to- stand after two weeks of performing the resistant exercises. The patient was able to walk after 4 weeks, and the patient's overall gait performance had improved after 8 weeks. All of the variables had improved after each week.

Conclusions: The results of this case study may be used to enhance future efforts to objectively evaluate resistant exercises during gait performance in persons affected by SLE.

Key Words: Gait, Lupus, Resistance exercise

\section{Introduction}

Systemic lupus erythematosus (SLE) is an autoimmune disease that causes inflammation and damage to various tissues of the body by forming antibodies due to an abnormality to the immune system [1]. The symptoms involved with SLE are varied and extensive, found in joints, skin, kidneys, heart, lungs, blood vessel, brain, etc., and it is rare to have the same symptoms from patient to patient [2]. Through the nervous system, It is reported that SLE can be involved in a variety of organ systems $[3,4]$.

Kaposi [5] first reported delirium in 2 of his 11 patients, Osler [6] reported a case of hemiplegia and delirium, and Libman and Sacks [7] reported a case of cerebral embolism due to these symptoms of the nervous system. Approximately $20 \%-50 \%$ of all patients with SLE has central nervous system

Received: 14 April, 2016 Revised: 8 June, 2016 Accepted: 9 June, 2016

Corresponding author: Youngkeun Woo

Department of Physical Therapy, College of Medical Science, Jeonju University, 303 Cheonjam-ro, Wansan-gu, Jeonju, Republic of Korea Tel: 82-63-220-3163 Fax: 82-63-220-2054 E-mail: ykwoo92@naver.com

(c) This is an Open-Access article distributed under the terms of the Creative Commons Attribution Non-Commercial License (http://creativecommons.org/licens es/by-nc/4.0) which permits unrestricted non-commercial use, distribution, and reproduction in any medium, provided the original work is properly cited.

Copyright $@ 2016$ Korean Academy of Physical Therapy Rehabilitation Science 
(CNS) involvement and of these cases, cerebral infarction and intracerebral hemorrhage is classified as a rare disease with only $7 \%$ of cases [8]. Also, there is no distinct correlation in the prevalence and etiology of CNS disease due to SLE, and each research results in different outcomes [9].

However, West [10] reported in the relationship between SLE and nervous system diseases can be caused by SLE in which a person's antibodies uses the immune system making it easier for a thrombosis to form in which the mechanisms of ischemic disease is active in the pathogenesis of stroke or convulsive disorders. Also, Devinsky et al. [11] found a significant decrease in the complement $\mathrm{C} 3$ and $\mathrm{C} 4$ in the serum of the SLE patient with CNS involvement.

There is a relationship between SLE patient with ischemic disease or hemorrhage with vessel damage. Karassa et al. [12] reported a significant increase in the incidence of complications of the nervous system with SLE patients with skin vasculitis lesions or arterial thromboses, therefore it was reported that there is a high correlation of CNS involvement and vascular disease in SLE patients. Also the pathological mechanism of SLE with brain infarct is associated with vasculitis [13].

Within the walls of the vessels the complex immune system is deposited triggering the complement activation causing vascular inflammation. This vascular inflammation is highly correlated with muscle calcification which will eventually cause muscle weakness. One of the characteristics of SLE patients is muscle weakness which impedes functional rehabilitation decreasing gait velocity and endurance and difficulty in independent postural change restricting functional mobility [14]. Also muscle weakness increases postural sway and instability in balance control [15] and increases the incidence of falls [16]. Fear of falls impedes independent activities of daily livings (ADLs) and also decreases quality of life [17].

The symptoms of SLE are time related therefore when there are no symptoms and when the symptoms are severe can be categorized as remission and flair respectively. Except during a flair, to alleviate the symptoms, regular exercise is recommended [2].

When looking at previous studies looking at SLE patients extension and aerobic exercises were the main types of exercises with effects of psychological fatigue, depression, and decrease in pain [18,19]. Ramsey-Goldman et al. [20] aerobic, range of motion (ROM), muscle strengthening, cardiopulmonary strength, physical function, bone density improved minimally. Kim [21] found that static exercises and muscle strengthening is recommended, but specific physical functional selective exercises were lacking in previous studies

Recent studies in SLE patients with infarct have not been studied and there are no studies that have done targeting specific strength exercises. Therefore, this case study, with a patient with SLE with infarct and complication with vasculitis leading to myotomy due to muscle calcification, it was found that LE resistive exercises increased functional level.

\section{Methods}

\section{Case study}

This case study is on a 30 years old male at hospital A in Gangwon province, with symptoms of whole body edema and whole body adynamia who is diagnosed with SLE. The patient was on dialysis due to thrombocytopenia and nephrotic syndrome and was unable to ambulate because of the whole body adynamia. In April 2013, while admitted to hospital A in Gangwon province, the patient had a right MCA infarction (CNS lupus) causing a left side hemiplegia due to SLE. In July 2013, the patient had an arteriovenous fistula operation on the common femoral artery-femoral vein due to necrotizing vasculitis of the L lower extremity (LE) with ongoing myonecrosis of the $\mathrm{L}$ anterior thigh and on July 22, 2013, he was transferred to the emergency room at hospital A in Seoul where he went back and forth from hospital A in Gangwon province to hospital A in Seoul until September 2013 where he had 16 myotomy procedures to remove the necrotic tissue of the $\mathrm{L}$ thigh. About $23 \mathrm{~cm}$ of the rectus femoris, $25 \mathrm{~cm}$ of the vastus medialis, $12 \mathrm{~cm}$ of the tensor fascia lata, and less than $3 \mathrm{~cm}$ from the anterior thigh was removed, after one year of recovery from the myotomy procedure, the patient came to hospital $\mathrm{R}$ in Seoul for rehabilitation therapy. Due to lack of strength, the patient was unable to transfer from sit to stand and needed maximal assist from the therapist to maintain a sitting position. For 8 weeks from May 4 to June 28 2015, this case subject participated in rehabilitation therapy and was able to maintain in sitting with supervision, however sit to stand was still not possible.

Pretest manual muscle test, right side U/E flexors were F, extensors were F-, L/E flexors were F-, extensors were F-. And left side U/E flexors were T, extensors were Z, L/E flexors were $\mathrm{T}$ and extensors were $\mathrm{Z}$ grade. Action of rectus femoris and vastus medialis were 45 degrees with passive knee extension, and tensor facia latae were 30 degrees with passive hip abduction and 10 degrees with passive hip flexion 
Table 1. Resistant exercise training session

\begin{tabular}{cll}
\hline Time & \multicolumn{1}{c}{ Session } & \multicolumn{1}{c}{ Training } \\
\hline $10 \mathrm{~min}$ & Warm up & $\begin{array}{l}\text { Stretching \& passive range of motion } \\
\text { exercise }\end{array}$ \\
$20 \mathrm{~min}$ & Work out & $\begin{array}{l}\text { Resistant exercise } \\
\text { Stretching \& massage }\end{array}$ \\
\hline
\end{tabular}

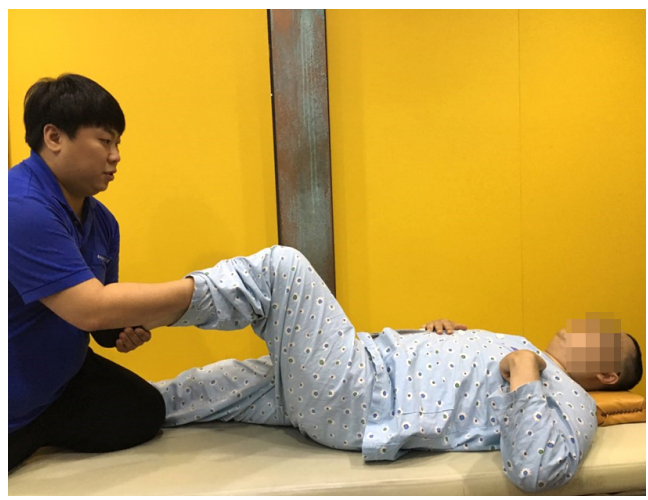

Figure 1. Resistance exercise of lower leg in supine position.

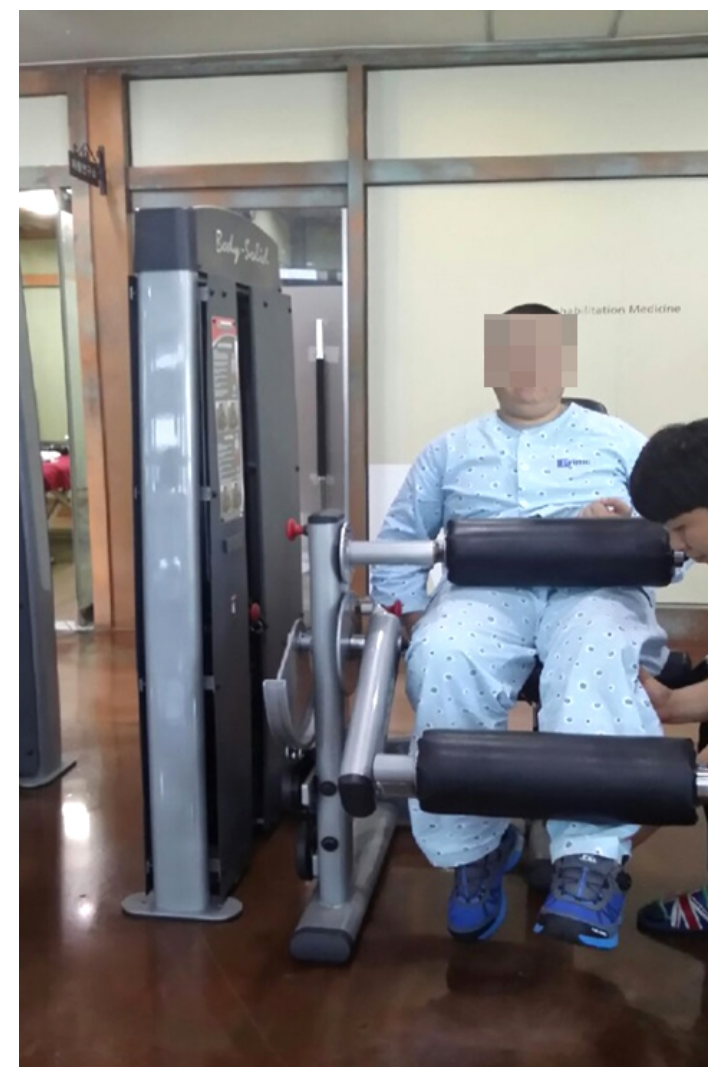

Figure 2. Resistance exercise of lower leg using press machine in sitting position 1.

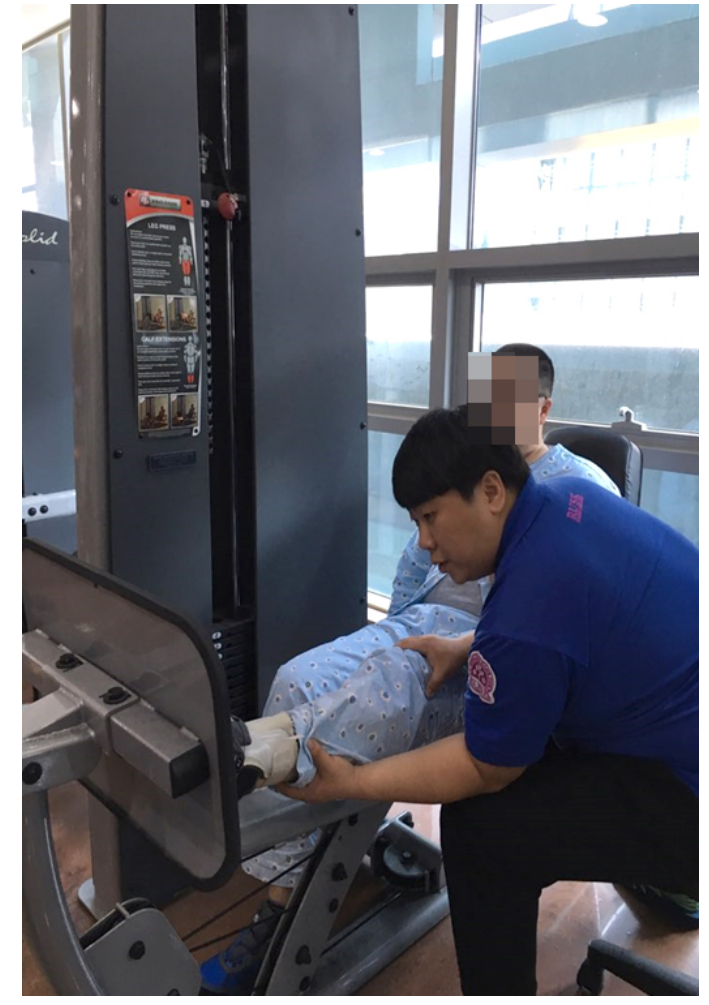

Figure 3. Resistance exercise of lower leg using press machine in sitting position 2 .

after myotomy.

\section{Procedure}

In this case study, progressive resistance exercise was used because the subject had a significant decrease in strength due to disease. The resistance exercises were performed five times a week, 40 minutes a day, in an independent area (such as rehabilitation after the treatment performed in hospitals) (Table 1).

Resistive exercises were completed after conventional physical therapy 5 times per week, 40 minutes per day (Table 1).

Resistance exercises were performed five times a week, 40 minutes a day after receiving rehabilitation therapy. The exercises were performed as appropriate to the situation of the subject in reference to research by Weiss et al. [22]. The first and second week (Figure 1), the exercises were completed in the supine and sitting positions (Figures 2, 3), and in the third week, when sit to stand was possible, the leg press machine was used in sitting to progress the amount of tolerance and exercises in standing were added (Figure 4). With the added standing exercises, exercises in supine were discontinued (Table 2) [23]. Frequency was set for the first 


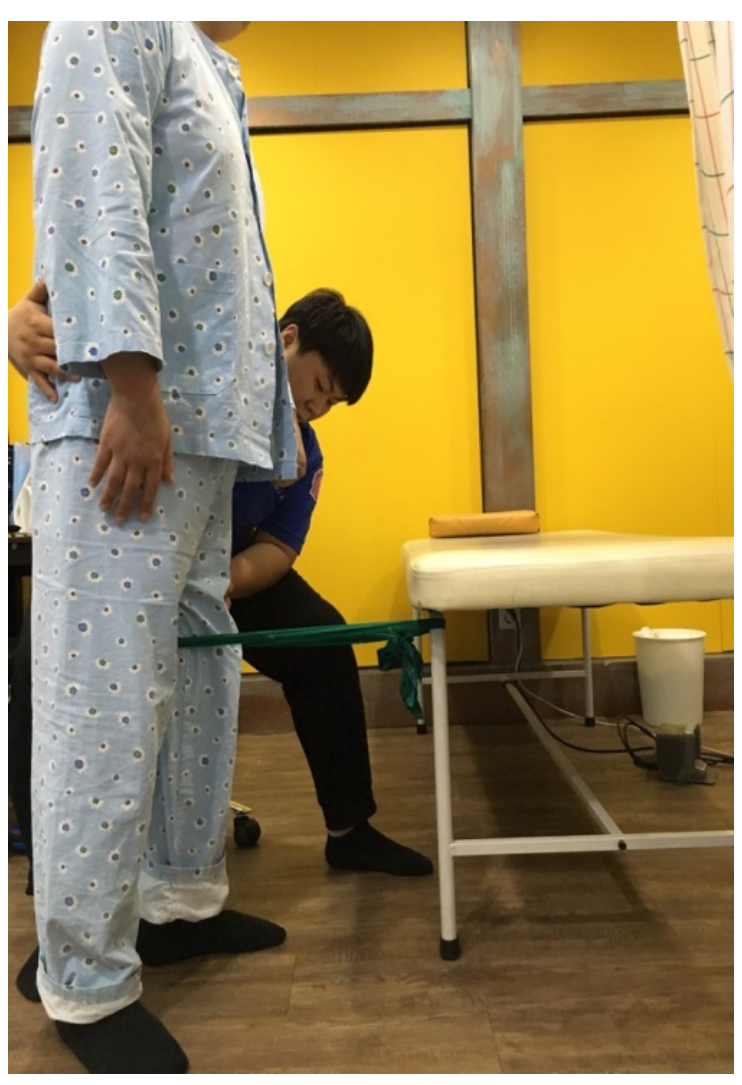

Figure 4. Resistance exercise of lower leg in standing position. and second week to 15 repetion maximum (15RM) of repetitions of resistance exercises [24]. The subject's LE muscle strength was less than $\mathrm{F}$, therefore open kinetic exercises were performed with the subject's active ROM, and was provided with active assistive and passive ROM to the joint's full ROM. Close kinetic exercises were performed by applying 15RM repetitions. Resistance exercises or passive joint alignment was provided for proprioception motion to take place. Close kinetic exercise resistance were given manually by the therapist at $15 \mathrm{RM}$. From 3 weeks to 8 weeks, the press machine (leg extension, leg press; Body Solid Inc., Forest Park, IL, USA) was used for sitting resistance exercises, and therabands (MSD-band 2M; MSD-Europe, Tisselt, Belgium) were used for standing resistance exercises. The lightest resistance, yellow and the next level of greater resistance, green therabands, were selected by the subject to complete 15RM for the 8-week period. Before moving on to the stronger resistant green theraband, the yellow theraband was tied progressively further away from the subject to increase the resistance of the yellow theraband to complete the 15RM, and when the subject was able to complete $15 \mathrm{RM}$ with the green theraband, the green theraband was used. From 3 weeks to 6 weeks, the yellow theraband was used, and in weeks 7 and 8 , the green theraband was used. The 15RM was re-measured every week.

Table 2. Progression of resistant exercises

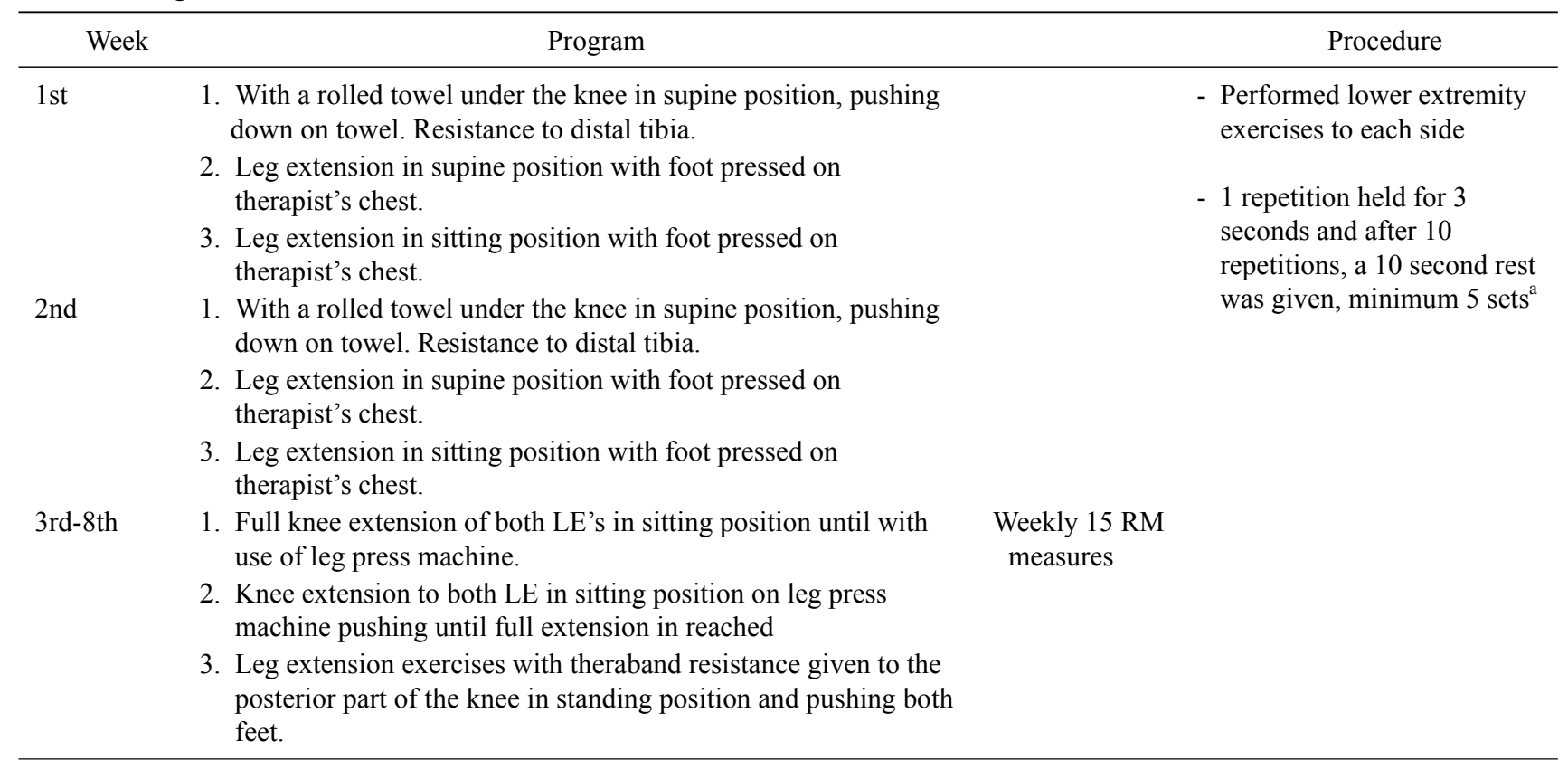

LE: lower extremity, 15RM: 15 repetion maximum.

${ }^{a}$ Represented from the article of Kim et al. [23]. 
To determine the subject's skill level with LE resistive exercises, 5-repetition sit-to-stand test (5RSST), timed up \& go (TUG), 10-meter walking test (10MWT) and spatio-temporal gait variables as gait speed, cadence, stride length of left side, double limb support of left side were each measured at the beginning of the program, 2 weeks, 4 weeks, and after 8 weeks.

\section{Methods}

\section{Outcome measures}

All tests were measured representative of the therapist who stood on affected side as a safety measure for falls. In addition, all tests were completed 3 times to obtain the average value.

\section{RSST}

5RSST was used to measure sit-to-stand. The subject was seated in a chair with a supported back with arms crossed across the chest and was asked to "please stand up and sit back down as fast as you can 5 times" [25]. After a verbal cue "start" the stopwatch began and after the 5th time to stand, the stopwatch was stopped [25].

Tester reliability of this test is $\mathrm{r}=0.97-0.98$, measurement tracking reliability is $\mathrm{r}=0.99$, test-retest correlation coefficient is found to be $\mathrm{r}=0.98-0.99$ [26].

\section{TUG}

To measure walking ability baseline, the subject was asked from a seated position with armrests to stand up and walk 3-meter, turn around, and walk back to the chair and sit down as time was measured. The Rater reliability with the TUG test in stroke patients $\mathrm{r}=0.99$ and interrater reliability was measured by $\mathrm{r}=0.98$ [27].

\section{MWT}

To obtain the subject's baseline walking ability, a 14-meter linear walking track was made. As the subject started, a stopwatch was used to measure for 10-meter trav- eled except 2-meter on each side [28]. Test-retest correlation coefficient was found to $\mathrm{r}=0.93$ [29].

\section{Spatio-temporal gait variables}

To measure the spatio-temporal gait variables, a 3 axes wireless accelerometer (BTS G-Walk; BTS Bioengineering, Garbagnate Milanese, Italy) was used and gait speed, cadence, stride length of left side, left side double limb support were measured. The accelerometer was securely fastened by an elastic band at the waist and gait was measured for $8 \mathrm{~m}$ by a Bluetooth connected computer. One tester stood at the start line with the subject while an additional tester was monitoring the computer screen. With a verbal cue "start" the tester monitoring the screen and the subject started the test at the same time and measurement of the accelerator and decelerator as soon as the subject crossed the 2 minutes mark and stopped the test once 6 minutes of data was collected. A verbal cue "stop" was given and both tester and subject stopped after 2 minutes more of walking. Reliability of gait velocity $r=0.99$ ICC $(r=0.98)$ for the number analysis showed the reliability intraclass correlation coefficient $r=0.99$ for cadence of stroke patients.

\section{Results}

Results of ability improvement before resistance exercises at pretest, after 2 weeks, after 4 weeks, and after 8 weeks is as follows (Table 3).

The 5RSST, TUG, and 10MWT times (seconds) have decreased significantly; (1) 5RSST at 2 weeks $134.57 \mathrm{sec}$, after 4 weeks $67.31 \mathrm{sec}$, after 8 weeks $38.97 \mathrm{sec}$, (2) TUG after 4 weeks $92.31 \mathrm{sec}$, after 8 weeks $38.97 \mathrm{sec}$, (3)10MWT after 4 weeks $87.92 \mathrm{sec}$, after 8 weeks $47.89 \mathrm{sec}$. Gait speed increased from $0.13 \mathrm{~m} / \mathrm{s}$ after 4 weeks to $0.42 \mathrm{~m} / \mathrm{s}$ after 8 weeks. Cadence increased from $11.84 \mathrm{steps} / \mathrm{min}$ after 4 weeks to $34.5 \mathrm{steps} / \mathrm{min}$ after 8 weeks. Stride length in-

Table 3. Change ability before resistant exercise and after $2 \mathrm{wk}, 4 \mathrm{wk}$, and $8 \mathrm{wk}$

\begin{tabular}{lcccc}
\hline \multicolumn{1}{c}{ Variables } & Pre & After 2 wk & After 4 wk & After 8 wk \\
\hline 5RSST $(\mathrm{sec})$ & - & 134.57 & 67.31 & 38.97 \\
TUG $(\mathrm{sec})$ & - & - & 92.31 & 32.65 \\
10MWT $(\mathrm{sec})$ & - & - & 87.92 & 47.89 \\
Speed $(\mathrm{m} / \mathrm{s})$ & - & - & 0.13 & 0.42 \\
Cadence $($ steps/min) & - & - & 11.84 & 34.5 \\
Stride length (m) & - & - & 0.71 & 1.32 \\
Double limb support (\%) & - & - & 44.1 & 37.5 \\
\hline
\end{tabular}

5RSST: 5-repetition sit-to-stand test, TUG: Timed Up \& Go, 10MWT: 10-meter walking test, -: impossible. 
creased from $0.71 \mathrm{~m}$ after 4 weeks to $1.32 \mathrm{~m}$ after 8 weeks. Double limb support decreased from $44.1 \%$ after 4 weeks to $37.5 \%$ after 8 weeks.

\section{Discussion}

Due to SLE, the subject in this case study acquired nephrotic syndrome accompanied by a right MCA infarction resulting in a very poor health condition however with continued dialysis, the subject improved his chances of survival. There after the subject acquired a commonly accompanied necrotizing vasculitis affecting the common femoral arteryfemoral vein of the left LE which resulted in a myotomy of the left LE anterior part of the thigh due to myonecrosis significantly decreasing LE strength.

A SLE patient with Central nervous system involvement has a decrease in velocity motor nerve conduction with slowed latent period at the end of F-wave, and does not display a response to stimulus [30].

In the initial stages of rehabilitation of this case study, decreased muscle strength with movement activation significantly decreased. It was easier to elicit movements complemented by joint/muscle alignment in order to perform LE resistance exercises for sensory stimulation, with passive ROM verbal cues. As a result, with time, close to full ROM was achieved by resistance exercises as well as the qualitative and quantitative improvements in the subjects ability to walk and sit-to-stand was observed.

Kim and Sohng [31] reported in a review study in evaluation in SLE patients should be set up on a regular exercise plan program and be referred to a physical therapist for evaluation to maintenance and increase strength in joint function if you are having musculature problems.

It is proposed that exercise interventions should be recognized as an important aspect of rehabilitation for SLE patients as indicated by this case study.

Up to now, psychological problems, pain, muscle fatigue, etc. have been identified as effects of joint ROM and aerobic exercises for the SLE patient. Clarke-Jenssen et al. [32] reported that 3 out of 6 SLE patients in his research had pain relief after treadmill exercises for 40 minutes at $70 \%$ maximum heart rate three times a week for 12 weeks. Also in a pilot study of 10 SLE patients split into two groups of 5, Ramsey-Goldman et al. [33] reported findings of improved bone mineral content in both groups after joint ROM/strengthening exercises. Tench et al. [34] reported findings of reduced fatigue after conducting a step-by-step aerobic exercise program for 12 weeks. Also, Kim [21] Presented a manual targeting SLE patients with the principle of effectiveness, overload, incremental load and stability in moderate exercise programs that include in swimming, biking, walking, and cardiovascular exercises. However, in this case study, with complications by symptoms involving the CNS leading to myotomy of the LE requiring aerobic exercises and joint ROM, a more muscle specific exercise regimen is needed rather than a general exercise program. Alternatively, we think that a patient should be able to complete sit-to-stand after of 2 weeks of BLE resistance exercises, and able to ambulate after 4 weeks of gradual increase in resistance, and show improvements in gait after 8 weeks.

Eight weeks after the experiment, although the speed for independence of $0.8 \mathrm{~m} / \mathrm{s}$ [35] was not achieved, $0.42 \mathrm{~m} / \mathrm{s}$ was recorded which is very close to the indoor speed set at $0.40 \mathrm{~m} / \mathrm{s}$ for independence. Healthy elderly gait speed of 1.4 $\mathrm{m} / \mathrm{s}$ and a gait speed of 1.07-1.22 m/s for independent street crossing was not achieved, however, it can be postulated that a stroke patient who is able to ambulate at a gait speed range of $0.18-1.03 \mathrm{~m} / \mathrm{s}$ will progress even further toward independence [36].

In this case study, a patient with SLE who presents with physical deterioration, resistance exercises is thought to be used as a cornerstone to promote improvements related to ADLs. However, it is difficult to generalize the positive effects of resistance exercises to all SLE patients without myotomy, cerebral vascular accident, and vasculitis. Future studies need to investigate the effects of applying selective resistance exercises to other body parts to similar SLE patients as in this case study and non-similar SLE patients.

\section{Conflict of Interest}

The authors declared no potential conflicts of interest with respect to the authorship and/or publication of this article.

\section{References}

1. Grossman JM, Kalunian KC. Definition, classification, activity, and damage indices. In: Wallace DJ, Hahn BH, editors. Dubois' lupus erythematosus. 6th ed. Philadelphia: Lippincott Williams \& Wilkins; 2002. p. 19.

2. Dall'Era M, Davis JC. Systemic lupus erythematosus. How to manage, when to refer. Postgrad Med 2003;114:31-7, 40.

3. Fields RA, Sibbitt WL, Toubbeh H, Bankhurst AD. Neuropsy- 
chiatric lupus erythematosus, cerebral infarctions, and anticardiolipin antibodies. Ann Rheum Dis 1990;49:114-7.

4. Denburg JA, Temesvari P. The pathogenesis of neuropsychiatric lupus. Can Med Assoc J 1983;128:257-60.

5. Kaposi M. Neue beitrage zur kenntmiss des lupus erythematosus. Arch f Derm u Syph 1872;4:36-78.

6. Osler W. On the visceral complications of the erythema excudativum multiforme. Am J Med Sci 1895;110:629-46.

7. Libman E, Sacks B. A hitherto undescribed form of valvular and mural endocarditis. Arch Intem Med 1924;33:701-37.

8. Park JW, Kim MS, Lee SI, Jung YT, Kim SC, Sim JH. Systemic Lupus Erythematosus with Central Nervous System Involvement: Case Report. J Korean Neurosurg Soc 1998;27:268-73.

9. Ainiala H, Loukkola J, Peltola J, Korpela M, Hietaharju A. The prevalence of neuropsychiatric syndromes in systemic lupus erythematosus. Neurology 2001;57:496-500.

10. West SG. Lupus and the central nervous system. Curr Opin Rheumatol 1996;8:408-14.

11. Devinsky O, Petito CK, Alonso DR. Clinical and neuropathological findings in systemic lupus erythematosus: the role of vasculitis, heart emboli, and thrombotic thrombocytopenic purpura. Ann Neurol 1988;23:380-4.

12. Karassa FB, Ioannidis JP, Touloumi G, Boki KA, Moutsopoulos HM. Risk factors for central nervous system involvement in systemic lupus erythematosus. QJM 2000;93:169-74.

13. Park HD. Serologic characteristics in systemic lupus erythematosus patients with neurologic disorder [Master thesis]. Seoul: Hanyang University; 2004.

14. Bohannon RW. Muscle strength and muscle training after stroke. J Rehabil Med 2007;39:14-20.

15. Laufer Y, Dickstein R, Resnik S, Marcovitz E. Weight-bearing shifts of hemiparetic and healthy adults upon stepping on stairs of various heights. Clin Rehabil 2000;14:125-9.

16. Geurts AC, de Haart M, van Nes IJ, Duysens J. A review of standing balance recovery from stroke. Gait Posture 2005;22:267-81.

17. Woollacott M, Shumway-Cook A. Attention and the control of posture and gait: a review of an emerging area of research. Gait Posture 2002;16:1-14.

18. An MJ, Park IH. Effect of stretching exercise on depression, pain, and fatigue in patients with systemic lupus erythematosus. J Muscle Jt Health 2006;13:43-52.

19. Tench C, Bentley D, Vleck V, McCurdie I, White P, D’Cruz D. Aerobic fitness, fatigue, and physical disability in systemic lupus erythematosus. J Rheumatol 2002;29:474-81.

20. Ramsey-Goldman R, Schilling EM, Dunlop D, Langman C, Greenland P, Thomas RJ, et al. A pilot study on the effects of exercise in patients with systemic lupus erythematosus. Arthritis Care Res 2000;13:262-9.

21. Kim MJ. Lupus; self-management and exercise. J Muscle Jt
Health 1999;6:360-9.

22. Weiss A, Suzuki T, Bean J, Fielding RA. High intensity strength training improves strength and functional performance after stroke. Am J Phys Med Rehabil 2000; 79:369-76; quiz 391-4.

23. Kim NJ, Kim HS, Oh JK, Lee BH. Effects of elastic band exercise on upper and lower electromyographic activity in stroke. Exerc Sci 2006; 15:329-35.

24. Prentice WE. Rehabilitation techniques in sports medicine. 5th ed. New York: McGraw-Hill Higher Education; 2010.

25. Meretta BM, Whitney SL, Marchetti GF, Sparto PJ, Muirhead RJ. The five times sit to stand test: responsiveness to change and concurrent validity in adults undergoing vestibular rehabilitation. J Vestib Res 2006;16:233-43.

26. Mong Y, Teo TW, Ng SS. 5-repetition sit-to-stand test in subjects with chronic stroke: reliability and validity. Arch Phys Med Rehabil 2010;91:407-13.

27. Podsiadlo D, Richardson S. The timed "Up \& Go": a test of basic functional mobility for frail elderly persons. J Am Geriatr Soc 1991;39:142-8

28. Dean CM, Richards CL, Malouin F. Walking speed over 10 meters overestimates locomotor capacity after stroke. Clin Rehabil 2001;15:415-21.

29. Caty GD, Arould C, Stoquart GG, Thonnard JL, Lejeune TM. ABILOCO: a Rash-built 13-item questionnaire to assess locomotion ability in stroke patients. Arch Phys Med Rehabil 2008;89:284-90.

30. Kim HS, Lee SC, Hong HI, Han KH, Lee SK, Kim SS. A case of neuropsychiatric lupus presenting as guillain-barre syndrome and cerebral infarction. J Korean Rheum Assoc 2004;11:411-6.

31. Kim MJ, Sohng KY. Nursing interventions of the lupus patient. J Muscle Jt Health 1995;2:197-208.

32. Clarke-Jenssen AC, Fredriksen PM, Lilleby V, Mengshoel AM. Effects of supervised aerobic exercise in patients with systemic lupus erythematosus: a pilot study. Arthritis Rheum 2005;53: 308-12.

33. Ramsey-Goldman R, Schilling EM, Dunlop D, Langman C, Greenland P, Thomas RJ, et al. A pilot study on the effects of exercise in patients with systemic lupus erythematosus. Arthritis Care Res 2000;13:262-9.

34. Tench CM, McCarthy J, McCurdie I, White PD, D'Cruz DP. Fatigue in systemic lupus erythematosus: a randomized controlled trial of exercise. Rheumatology (Oxford) 2003;42:1050-4.

35. van de Port IG, Kwakkel G, Lindeman E. Community ambulation in patients with chronic stroke: how is it related to gait speed? J Rehabil Med 2008;40:23-7.

36. Kirschbaum JB, Axelson PW, Longmuir PE, Mispagel KM, Stein JA, Yamada DA. Designing sidewalks and trails for access: part II of II: best practices design guide. Washington DC: Federal Highway Administration; 2001. 